\title{
Assessment of Knowledge Regarding Oral Hygiene among Parents of Pre-School Children Attending Pediatric Out Patient Department in Dhulikhel Hospital Khanal K, ${ }^{1}$ Shrestha $D,{ }^{2}$ Ghimire $N,{ }^{3}$ Younjan $R,{ }^{4}$ Sanjel $S^{1}$
}

${ }^{1}$ Department of Community Medicine

${ }^{2}$ Department of Conservative Dentistry and Endodontics

${ }^{3}$ Department of Pedodontics and Preventive Dentistry

${ }^{4}$ Department of Nursing

Kathmandu University School of Medical Sciences

Dhulikhel, Kavre, Nepal

\section{Corresponding Author}

Kishor Khanal

Department of Community Medicine

Kathmandu University School of Medical Science

Dhulikhel, Kavre, Nepal

E-mail: khanalkishorst@gmail.com

\section{Citation}

Khanal K, Shrestha D, Ghimire N, Younjan R, Sanjel $\mathrm{S}$. Assessment of Knowledge Regarding Oral Hygiene among Parents of Pre-School Children Attending Pediatric Out Patient Department in Dhulikhe Hospital. Kathmandu Univ Med J 2015;49(1):38-43.

\begin{abstract}
\section{Background}

Level of knowledge regarding oral hygiene among the parents of pre-school children plays an important role on maintaining the good oral hygiene of their children. In Nepal, sufficient research has not been carried out on this area.
\end{abstract}

\section{Objective}

Objective of this study is to assess the level of knowledge on oral hygiene of preschool children's parents attending pediatric outpatient department in Dhulikhel Hospital.

\section{Method}

A descriptive study was conducted from November 2012 to January 2013 among one hundred parents of preschool children visiting pediatrics outpatient department of Dhulikhel Hospital. Paper and pencil based semi structured questionnaire was used for collecting data. Questions related to demographic information and knowledge were asked. Thirty questions were used for assessing knowledge level. Knowledge score was calculated by allocating one point for each correct answer and zero point for each wrong answer. Analyzed data were presented in terms of numbers and percentages. Total knowledge scores were categorized based on percentage. Knowledge score was categorized on four group - exclusive intervals - namely-poor (0-40\%), moderate (40-60\%), good (60-80\%) and excellent (80-100\%). Mann-Whitney $\mathrm{U}$ test and Kruskal-Wallis test were applied to check significance difference and chisquare test was used to check association among different background characteristic.

Result

It was found that $81 \%$ had moderate knowledge, $15 \%$ had poor knowledge and $4 \%$ had good knowledge about oral hygiene. Median knowledge score was found to be 15 with range 10 to 21 . Following variables were found to be significant difference on knowledge category: Education status $(p<0.001)$, education level $(p=0.041)$, past experience about oral health problem $(p=0.008)$, Further significant association was found between knowledge category and educational status $(p<0.001)$ and between knowledge category and past experience $(p<0.001)$.

\section{Conclusion}

Knowledge regarding oral hygiene was found satisfactory among the parents of preschool children visiting pediatric OPD of Dhulikhel Hospital.

\section{KEY WORDS}

Knowledge, oral health, parents, pre-school children 


\section{INTRODUCTION}

According to World Health Organization, "Oral health is a state of being free from chronic mouth and facial pain, oral and throat cancer, oral sores, birth defects such as cleft lip and palate, periodontal (gum) disease, tooth decay and tooth loss, and other diseases and disorders that affect the oral cavity". ${ }^{1}$ Risk factors for oral diseases include unhealthy diet, tobacco use, alcohol use, and poor oral hygiene. ${ }^{1}$ Oral health means more than just healthy teeth affecting people physically and psychologically, and how it influences their growth, function, speech, esthetics, and socialize, as well as their feelings of social well-being. ${ }^{2}$ Oral health is important for good health and well-being of individuals which covers a range of health promotion and disease prevention concerns. It is important issue which needs continuing supervision for the health care professional., ${ }^{3,4}$ Good oral health habits in childhood are shaped by parents, especially by mothers. ${ }^{4}$ In the early childhood years, parents are the primary social force influencing child development and parents with higher education have more control on children's health behavior compared to low educated parents. ${ }^{5}$

Children under the age of 5 years generally spend most of their time with parents and guardians. These early years involve "primary socialization" during which the earliest childhood routines and habits are acquired. ${ }^{6}$ During the first three years and pre -school period role of parents is very important on maintaining good oral health of child ,because they are the main caregivers of oral health. ${ }^{7}$ This includes eating and drinking habits of child and healthy behavior established as norms in the home and it relies on the knowledge and behavior of parents and elder siblings. ${ }^{7}$ Besides parents role, some other factors such as maternal education, occupation and current knowledge also plays vital role on determining oral health of their children. ${ }^{6}$ Risk factors for oral diseases are broadly classified into biological and social risk factors, ${ }^{8}$ and social risk factors comprise low parental education, low socio-economic status and lack of awareness about dental diseases. ${ }^{9}$

Among different oral health problems, dental caries is one of the major problems in the world and World Health Organization reports $60-90 \%$ of schoolchildren worldwide have experienced dental caries, with the disease being most prevalent in Asian and Latin American countries. ${ }^{10}$ In India, the prevalence of caries among preschool children was found to be in range of $40-70 \% .{ }^{11-14}$ According to the survey conducted in Nepal, $58 \%$ of 5-6 year old school children suffer from dental caries. ${ }^{15}$ Dental caries is a serious public health problem in developing countries and it begins early in life which have long term effect on quality of life of the children and family and is associated with bad oral health habits. ${ }^{2}$

Since Nepali children have low level of oral health awareness and practices as compared to western children, ${ }^{16}$ and knowledge of parents have direct role on this. ${ }^{3-5}$ The objective of this study was to assess what parents already know about children's oral health promotion activities and oral health knowledge and its relationship with sociodemographic characteristic from the sample of parents of preschool children visiting pediatrics OPD of Dhulikhel Hospital.

\section{METHODS}

A descriptive study was conducted from November 2012 to January 2013 among parents of preschool children (3-6 years of age) visiting pediatrics OPD of Dhulikhel Hospital. This study has been approved by the Institutional Review Committee, Kathmandu University School of Medical Sciences (IRC/KUSMS). Many parents from rural and urban areas of Kavre and other districts (particularly from Bhaktapur and Sindhupalanchok) visit this hospital with their children for checkup and treatment.

Sample size for this study was determined by using $n=Z^{2} p q / d^{2}$, where $\mathrm{Z}=1.96$, value of $\mathrm{p}$ is taken as 0.5 , allowable error $(\mathrm{d})=0.2$ and $\mathrm{n}$ is required sample size. Based on these parameters, the required sample size was 96 and taking $4 \%$ as non response total 100 parents were purposively selected and interviewed.

A pretested and paper and pencil based semi structured questionnaire was used for collecting data which consists of following parts: Demographic information, Knowledge regarding general information of oral hygiene, Knowledge regarding oral hygiene of the children, knowledge regarding dietary habit of the children and knowledge regarding role and responsibility of the parents in maintaining oral hygiene of their children. Interview method (face to face) was used to collect data.

Prior to interview, informed consent was taken from the parents and objectives of the study were clearly explained to them and confidentiality of data was assured to them. Parents were excluded if they were unable to understand Nepali language because Nepali language was used during interview. Collected data were entered on MS-Excel and analyzed using SPSS version 20. Socio-demographic and other quantitative data were summarized and presented using numbers and percentage. Knowledge score was calculated by allocating one point for each correct answer and zero point for each wrong answer. Then, calculated total knowledge scores were divided in four categories (exclusive class intervals) based on percentage- poor knowledge (0-40\%), moderate knowledge (40-60\%), good knowledge (60-80\%) and excellent knowledge (80-100\%). ${ }^{10}$ Further, knowledge score were adjusted and only two categories were formed; parents having poor knowledge (0$40 \%$ ) and parents having moderate or good knowledge (40$100 \%)$. This was done to simplify our analysis. Further, we measured association between demographic characteristics and adjusted knowledge categories using Chi-Square Test. Mann-Whitney $U$ test and Kruskal-Wallis ANOVA were carried out for test of significance of knowledge score among different demographic characteristic. Throughout the study, level of significance was set up 0.05 . 
Table 1. Knowledge Score on Oral Hygiene among different variables

\begin{tabular}{|c|c|c|c|c|c|c|}
\hline Variables & & $\begin{array}{c}\text { Minimum Knowledge } \\
\text { Score }\end{array}$ & $\begin{array}{c}\text { Maximum Knowledge } \\
\text { Score }\end{array}$ & Median Score & Interquartile Range & P-Value \\
\hline Relation & $\begin{array}{l}\text { Father } \\
\text { Mother }\end{array}$ & $\begin{array}{l}10 \\
10\end{array}$ & $\begin{array}{l}20 \\
21\end{array}$ & $\begin{array}{l}15 \\
15\end{array}$ & $\begin{array}{l}3 \\
3\end{array}$ & $0.969 *+$ \\
\hline Ethnicity & $\begin{array}{l}\text { Brahmin } \\
\text { Chhetri } \\
\text { Newar } \\
\text { Tamang } \\
\text { Others }\end{array}$ & $\begin{array}{l}11 \\
12 \\
10 \\
10 \\
12\end{array}$ & $\begin{array}{l}19 \\
20 \\
21 \\
17 \\
15\end{array}$ & $\begin{array}{l}16 \\
15 \\
15 \\
15 \\
13\end{array}$ & $\begin{array}{l}4 \\
2 \\
3 \\
5 \\
2\end{array}$ & $0.115^{*}++$ \\
\hline Occupation & $\begin{array}{l}\text { Agriculture } \\
\text { Business } \\
\text { Service } \\
\text { Housewife } \\
\text { Others }\end{array}$ & $\begin{array}{l}10 \\
13 \\
10 \\
10 \\
11\end{array}$ & $\begin{array}{l}18 \\
21 \\
20 \\
19 \\
17\end{array}$ & $\begin{array}{l}14 \\
16 \\
15 \\
15 \\
15\end{array}$ & $\begin{array}{l}4 \\
1 \\
3 \\
4 \\
4\end{array}$ & $0.093^{*++}$ \\
\hline $\begin{array}{l}\text { Past experience about } \\
\text { oral health problems }\end{array}$ & $\begin{array}{l}\text { Yes } \\
\text { No }\end{array}$ & $\begin{array}{l}10 \\
10\end{array}$ & $\begin{array}{l}21 \\
17\end{array}$ & $\begin{array}{l}16 \\
15\end{array}$ & $\begin{array}{l}3 \\
2\end{array}$ & $0.008^{* *}+$ \\
\hline Educational Status & $\begin{array}{l}\text { Literate } \\
\text { Illiterate }\end{array}$ & $\begin{array}{l}12 \\
10\end{array}$ & $\begin{array}{l}21 \\
15\end{array}$ & $\begin{array}{l}16 \\
13\end{array}$ & $\begin{array}{l}3 \\
2\end{array}$ & $<0.001 * *_{+}$ \\
\hline $\begin{array}{l}\text { Education } \\
\text { Level }\end{array}$ & $\begin{array}{l}\text { Primary } \\
\text { Lower Secondary } \\
\text { Secondary } \\
\text { Higher Secondary } \\
\text { Bachelors and Above }\end{array}$ & $\begin{array}{l}12 \\
15 \\
15 \\
14 \\
16\end{array}$ & $\begin{array}{l}17 \\
18 \\
18 \\
19 \\
19\end{array}$ & $\begin{array}{c}15 \\
16 \\
16 \\
16.5 \\
16.5\end{array}$ & $\begin{array}{c}0.5 \\
1 \\
1 \\
4 \\
2\end{array}$ & $0.041^{* *++}$ \\
\hline $\begin{array}{l}* \text { Not significant } \\
* * \text { Significant } \\
+ \text { Man-Whitney U test } \\
++ \text { Kruskal -Wallis H }\end{array}$ & & & & & & \\
\hline
\end{tabular}

\section{RESULTS}

Among 100 parents, 59\% were Mother. Most of the parents were from Brahmin community (31\%) followed by Newar (28\%) and Chhetri (25\%). Majority of the parents were from joint family (51\%). Sixty-six percentages of parents were literate. Out of 59 mothers, most of them are housewives (34\%) and out of 41 fathers most of them have farming profession (15\%) followed by business profession (13\%).

More than half ( $58 \%$ ) of the parents had some experience about oral health problem of their children and out of them $88 \%$ had experience about Dental Caries. Peer group and friend circle $(51 \%)$ is the major source of information about oral hygiene followed by radio/TV (41\%). Out of hundred, $32 \%$ percent of parents understood that oral hygiene is 'cleanness of teeth, gum and tongue. Fifty six percent of parents said that appropriate age to clean teeth of child is 1-3 years followed by $4-5$ years (29\%). All of the parents agreed that knowledge regarding oral hygiene is important because it teach them to keep mouth, teeth, and gum clean. Majority of parents were familiar with oral health problems, among the problems, Dental Caries was most familiar oral health problem (91\%) among parents

Seventy-Six percent of the respondents said that their kids brush teeth twice a day followed by once a day (14\%) and more than two times (10\%). Thirty-six percent of parents had heard about fluoride content in toothpaste. Fifteen percent said fluoridated in toothpaste makes the teeth strong. About half of the parents (49\%) said that teeth should be brushed 2-3 minutes. When asked about Best time for brushing teeth $75 \%$ said that it is after taking lunch and before going to bed, followed by early morning (16\%). Ninety-three percent said that brush should be changed regularly. More than half of the parents (52\%) said that brush should be changed every 2-4 months, followed by after six months (28\%). More than two third of the parents (70\%) said appropriate amount of tooth paste for brushing kids teeth is about the size of a pea followed by $2 / 3^{\text {rd }}$ size of the brush (22\%).

Regarding main causes of oral/ dental problems, majority said that having excessive sweet, ice-cream and chocolate $(65 \%)$ is the main cause of dental problem followed by not brushing teeth and not cleaning mouth (53\%), and eating stale food (5\%). Majority of the parents (67\%) said that citrus fruits and green leafy vegetables promotes good oral health followed by meat, fish and cereal (33\%).All parents said that it is necessary to clean/rinse the child mouth after feeding/having food.

All parents know that it is necessary to educate the child with oral health hygiene and dental education and all agreed that parents should guide their children in maintaining good oral hygiene. Larger proportion of the parents (70\%) said correct way of brushing teeth is upward and downward direction followed by straight (23\%), circular with inner and outer side (5\%) and two percentage don't have any idea. All parents agreed that knowledge on maintenance of good oral hygiene improves oral health of their children. If there is oral health/dental problem, $69 \%$ of Parents take their child to dentist and 31\% visit general doctor. All parents agreed that children should be taken to dentist or doctor 
for checkup but regarding how often there was variation on answer as- if necessary (61\%), twice a year (20\%) and once a year(19\%). All parents said that first dental visit of the child should be at the age of six months (3\%), at one year (19\%), at the age of two years $(4 \%)$, at the age of three years(1\%), and don't know(73\%).

It was found that majority (81\%) have moderate knowledge about oral hygiene followed by poor knowledge (15\%) and good knowledge (4\%). According to the study it was found that $85 \%$ of parents have moderate or more than moderate knowledge but not on excellent level, and $15 \%$ of parents have poor knowledge regarding oral hygiene. Median knowledge score regarding knowledge about oral hygiene was found to be 15 with range 10 to 21 whereas total knowledge score was 30 . Following variables were found to be significant difference on knowledge category: Literacy $(P<0.001)$, education level $(P<0.05)$ and past experience about oral health problem $(P=0.008)$. Further significant association was found between knowledge category and educational status $(p<0.001)$ and between knowledge category and past experience $(p<0.001)$.

\section{DISCUSSION}

This is one of the few studies carried out in Nepal to assess the knowledge of pre-school children's parents regarding the oral health. A good understanding of parental knowledge regarding oral health is essential for improving children's oral health. Parents oral health related knowledge are associated with their children's oral health and parental level of education has been shown to be one of the most important determinants for children's oral health in many countries. ${ }^{17-19}$

In this study 100 parents were interviewed, out of them majority were mother (59\%). In similar study carried out by Chhabra et al. among 620 parents of pre-school children in India majority were mother $(81.3 \%),{ }^{20}$ but in the study carried out by Thakare et al. in Gujarat, India majority $(67.5 \%)$ were father. ${ }^{21}$ This shows that on some society father are more active on taking their child on hospital, while on others mother. Tooth brushing habits, use of fluoridated toothpaste, frequency and duration of tooth-brushing, are the most important factors on oral self-care behaviors. Brushing teeth is the most appropriate and effective oral hygienic habits. Brushing teeth twice daily after meal has been accepted recommendation for prevention of oral diseases and brushing is the most appropriate and effective oral hygiene habit. ${ }^{22-27}$ In our study $76 \%$ of the respondents had knowledge that child teeth should be brushed twice a day which is more higher than the study done by, Qiu et al. in southern china (67.3\%), ${ }^{28}$ Chhabra et al. and Babu in India: $11.8 \%$ and $42.62 \%$ respectively. ${ }^{20,29}$ In our study $15 \%$ of the respondent said that fluoride makes the teeth strong, which is smaller compared to the study done in India on which $30.1 \%$ said that fluoride helps to prevent tooth decay. ${ }^{20}$ In the current study $98 \%$ of the respondent used toothbrush and toothpaste for brushing teeth which is higher than the study done by Chhabra et al. (32\%). ${ }^{20}$ and Pullishery et al. (47\%). ${ }^{30}$ Tooth brushing less than twice a day or frequent sugary snacking or both, are associated with dental caries; frequency of tooth brushing and dental caries are negatively associated, and frequency of sugar consumption and dental caries are positively associated. ${ }^{31-33}$ Regarding the dietary habits, in the present study, $65 \%$ of the respondent answered excessive sweets and ice-cream is the main cause of oral problems, which is similar to the study done in India (70.2\%). ${ }^{20}$ For pre-school and young children, sugar intake should not be more than $30 \mathrm{~g} /$ person/day. ${ }^{25}$

According to the studies, prolonged use of bottle milk may develop caries and lose their deciduous teeth early and is called early childhood caries, ${ }^{34}$ however, baby bottle use and caries risk is not strong, and no concrete recommendations can be made about limiting bottle use, prolonged bottle use or putting child to bed with a bottle to prevent caries. ${ }^{34}$ Out of 100 respondent, only $29 \%$ of the respondent had knowledge that prolonged and frequent bottle feeding affect dental health which is larger than the study done by Chabra (26.1\%) and 93\% of the respondent had knowledge that it is not a good practice to put the baby in bed with milk bottle, which is higher than the study carried out in India(29.5\%). ${ }^{20}$

Several independent studies along with American Academy of Pediatric Dentistry have recommended early dental visits for children should ideally be before completion of one year of age or within 6 months of eruption of primary teeth and this is strongly supported by the American Dental Association..$^{35-39}$ In our study it was found that parents knowledge about first dental visit of the child should be before the age of one year (22\%) which was higher than the study done by Chabra et al. (15.2\%), ${ }^{20}$ and Hussein et al. $(12.5 \%) \cdot{ }^{40}$

According to our study distribution of parents according to knowledge score were found as: parents having poor knowledge score (15\%), moderate knowledge score (81\%), and good knowledge score (4\%) but the same distribution was found to be different on research done by Ghajari et al. ${ }^{41}$

Significant difference was found between oral hygiene knowledge score and educational status and education level ( $p=0.001, p=0.041)$, which is similar to the findings done by Williams et al. ${ }^{42}$, but in our study no significant difference was found between oral hygiene knowledge score and sex of parents $(P=0.969)$ which is different than the findings of research carried out by Jain et al. ${ }^{43}$ and Nagarajappa et al. ${ }^{44}$ 


\section{CONCLUSION}

Knowledge regarding oral hygiene was found satisfactory among the parents of preschool children visiting pediatric OPD of Dhulikhel Hospital. Parents' education status, education level and past experience on children's oral health problems differs significantly on knowledge category. For comprehensive assessment of this prevailing issue both qualitative and quantitative studies, on a large scale, are essential.

\section{REFERENCES}

1. World Health Organization, Oral health [Internet]; [cited 25th July 2014]. Available from: http://www.who.int/topics/oral_health/en/.

2. Hakan C, Çoruh TD, Mehmet D, Mustafa HM. Early childhood caries update: a review of causes, diagnoses, and treatments. Journal of natural science, biology, and medicine 2013; 4.1: 29.

3. Green M. Bright Futures: Guidelines for Health Supervision of Infants, Children, and Adolescents. National Maternal and Child Health Clearinghouse 1994.

4. Adeniyi $\mathrm{AA}$, Ogunbodede $\mathrm{OE}$, Jeboda OS, and Folayan OM. Do maternal factors influence the dental health status of Nigerian preschool children? International Journal of Paediatric Dentistry 2009; 19(6): 448-454.

5. Hooleya M, Skouterisa H, Boganina C, Saturb J, and Kilpatrickc N. Parental influence and the development of dental caries in children aged 0-6 years: a systematic review of the literature. Journal of Dentistry 2012; 40(10): 787-872.

6. Holm AK. Caries in the preschool child international trends. Journal of dentistry 1990; 18(6): 291-5.

7. Elham B, Hajizamani A, and Mohammadi TM. Oral health behavior of parents as a predictor of oral health status of their children 2013.

8. Berg JH, Slayton RL. Early Childhood Oral Health, Wiley-Blackwell, Singapore 2009.

9. Hallett KB, O'Rourke PK. Social and Behavioural Determinants of Early Childhood Caries. Aust Dent J 2003; 48(1): 27-33.

10. Petersen PE, Bourgeois D, Ogawa H, Estupinan-Day S, Ndiaye C.The global burden of oral diseases and risks to oral health. Bull World Health Organ 2005; 83:661-9.

11. Jose B, King NM. Early childhood caries lesions in preschool children in Kerala, India. Pediatr Dent 2003; 25:594-600.

12. National Oral Health Survey and Flouride Mapping, 2002-2003. New Delhi: Dental Council of India, Ministry of Health and Family Welfare, Govt. of India, 2004; 32: 67-78.

13. Ali YA, Chandranee NJ, Khan A, Khan ZH. Prevalence of dental caries in nursery school children of Akola city. J Ind Soc Pedo Prev Dent 1998; 16(1): 21-5.

14. Mandal KP, Tiwari AB, Chawla HS, Gauba KD. Prevalence and severity of dental caries and treatment needs among population in the Eastern states of India. J Ind Soc Pedo Prev Dent 2001; 19 (3): 85-91.

15. Yee R, Mishra P: Nepal Oral National Pathfinder Survey 2004. Int Dent J 2006; 56:196-02.

16. Humagain M. Evaluation of Knowledge, Attitude and Practice (KAP) About Oral Health Among Secondary Level Students of Rural Nepal - A Questionnaire Study. WebmedCentral DENTISTRY 2011;2(3):WMC001805 doi: 10.9754/journal.wmc.2011.001805

17. Petersen PE, Poulsen VJ, Ramahaleo J, Ratsifaritara C. Dental caries and dental health behaviour situation among 6- and 12-year-old urban schoolchildren in Madagascar. Afr Dent J 1991;5:1-7.

\section{ACKNOWLEDGEMENT}

The authors would like to thank all the parents who participated in this study and Associate Professor Dr. Parbodh Risal, Assistant Professor Dr. Rajiv Shrestha and Lecturer Kedar Manandhar for critical review of the manuscript.

18. Petersen PE. Oral health behavior of 6-year-old Danish children. Acta Odontol Scand 1992; 50:57-64.

19. Petersen PE . Sociobehavioural risk factors in dental cariesinternational perspectives. Community Dent Oral Epidemiol 2005; 33:274-279.

20. Chhabra N, Chhabra A. Parents knowledge, attitudes and cultural belief regarding oral health and dental care of preschool children in an Indian population. European Archives of paediatric dentistry. 2012;13(2).

21. Thakare VG, Ajith Krishnan CG, Chaware S. Parents' perceptions of factors influencing the oral health of their preschool children in Vadodara city, Gujarat: A descriptive study. Eur J Gen Dent 2012;1: 44-9

22. Lewis DW, Ismail AI. Prevention of periodontal disease. The clinical guide to preventive health care, the Canadian task force on periodic health examination. Minister of supply and services:Ottawa, 1994.

23. Löe $H$. Oral hygiene in the prevention of caries and periodontal disease. Int Dent J 2000;50: 129-139.

24. Brothwell DJ, Jutai DK, Hawkins RJ. An update of mechanical oral hygiene practices: Evidencebased recommendations for disease prevention. J Can Dent Assoc 1998; 64:295-306.

25. Sheiham A. Dietary effects on dental diseases. Public Health Nutr 2001; 4:569-91.

26. Honkala E. Oral health promotion with children and adolescents. In: Schou L, Blinkhorn AS (eds). Oral health promotion. New York: Oxford University Press, 1993; 169-187.

27. Vehkalahti MM, Widström E. Teaching received in caries prevention and perceived need for best practice guidelines among recent graduates in Finland. Eur J Dent Educ 2004;8:7-11.

28. Qiu RM, Wong MC, Lo EC, \& Lin HC. Relationship between children's oral health-related behaviors and their caregiver's sense of coherence. BMC public health 2013; 13(1): 239.

29. Babu J. Dental caries and oral hygiene practices of children and caregivers inKerala, India. Diss. The University of Hong Kong (Pokfulam, Hong Kong), 2001.

30. Pullishery F, Panchamal GS, Shenoy R. Parental Attitudes and Tooth Brushing Habits in Preschool Children in Mangalore, Karnataka: A Cross-sectional Study. Int J Clin Pediatr Dent 2013;6(3):156-60.

31. Fabien V, Obry-Musset AM, Hedelin G, Cahen PM. Caries prevalence and salt fluoridation among 9-year-old schoolchildren in Strasbourg, France. Community Dent Oral Epidemiol 1996; 24:408-11.

32. Flinck A, Källestål C, Holm AK, Allebeck P, Wall S. Distribution of caries in 12-year-old children in Sweden. Social and oral healthrelated behavioural patterns. Community Dent Health 1999;16:160-5.

33. Vanobbergen J, Martens L, Lesaffre E, BogaertsK, Declerck D. Assessing risk indicators for dental caries in the primary dentition. Community Dent Oral Epidemiol 2001;29:424-34. 
34. Reisine ST, Psoter W. "Socioeconomic status and selected behavioral determinants as risk factors for dental caries." Journal of Dental Education 2001; 65(10): 1009-16.

35. Widmer R. The first dental visit: an Australian perspective. Int J Paediatr Dent 2003;13:270

36. Rayner JA. The first dental visit: A UK viewpoint. Int J Paediatr Dent 2003;13:269

37. Nainar SM, Straffon LH. Targeting of Year One dental visit for Unite States children. Int J Paediatr Dent 2003;13:258-63

38. Douglass JM, Douglass AB. Infant oral health education for pediatric and family practice residents. Pediatr Dent 2005; 27:4.

39. Policy of Dental Home, Oral Health Policies, AAPD - Reference Manual 2004-2005

40. Hussein AS, Abu-Hassan MI, Schroth RJ \& Ghanim A M. Parent's Perception on the Importance of their Children's First Dental Visit (A cross-sectional Pilot Study in Malaysia). Journal of Oral research 2013; 1(1) :17-25
41. Ghajari M F, Mojtahedzadeh S, Kharazifard MJ, Mahdavi B \& Mohtavipour S. Evaluation of Knowledge, Attitude and Practice of Parents of Child-ren with Cardiac Disease about Oral Health. Journal of Islamic Dental Association of IRAN (JIDAI) 2014;25(4):4.

42. Williams NJ, Whittle JG, \& Gatrell AC. The relationship between socio-demographic characteristics and dental health knowledge and attitudes of parents with young children. British dental journal 2002; 193(11): 651-4.

43. Jain R, Oswal KC., \& Chitguppi R. Knowledge, attitude and practices of mothers toward their children's oral health: A questionnaire survey among subpopulation in Mumbai (India). Journal of Dental Research and Scientific Development 2014; 1(2): 40-5.

44. Nagarajappa R, Kakatkar G, Sharda AJ, Asawa K, Ramesh G \& Sandesh $N$. Infant oral health: Knowledge, attitude and practices of parents in Udaipur, India. Dental research journal 2013; 10(5): 659. 